\title{
Shock escape vs food-rewarded running in a successive discrimination
}

\author{
LYNN J. HAMMOND and JOAN HARMAN \\ Temple University, Philadelphia, Pennsylvania 19122
}

\begin{abstract}
Two groups of rats were trained for 100 trials on a successive discrimination in a runway where on half the trials $(\mathrm{S}-$ ) nonreinforcement was preceded by an alleyway cue of darkeness or ambient lighting. One group of hungry rats received food as a reward on S+ trials; while the other group of unhungry rats were shocked in the same runway and reinforced on $\mathrm{S}+$ trials by shock termination in the goalbox, but nonreinforced by 30 sec delay of shock termination on $\mathrm{S}$ - trials. Rats given the appetitive training learned the discrimination within 20-30 trials, while those given aversive training showed no evidence of forming a discrimination.
\end{abstract}

The major concern of the small but important literature on the nature of negative reinforcement has been to demonstrate that negatively reinforced behavior reveals the same basic phenomena as positively reinforced behavior. The typical finding has supported the notion that positive and negative reinforcement follow similar if not identical laws (e.g., see Church, 1971, Pp. 720-725).

However, experimenters in this area have often gone to ingenious lengths to demonstrate this symmetry between the two kinds of reinforcement; for example, there is the development of a complex cold water escape apparatus by Woods and his associates at Hollins College, which probably reduced many of the competing elicited response effects in shock escape studies. Without detracting from this obvious symmetry between the effects of reward and relief, it should also be noted that asymmetry exists as well; and that these asymmetrical effects are very important too for our understanding of appetitive and aversive learning.

For example, Lambert and Hammond (1970a) found that frustrated rats slowed down in a shock-escape double alleyway rather than speeding up as they do in typical studies of Amselian frustration in the reward runway. Hammond and Lambert (1970) found that long delays of reinforcement in a shock-escape runway ( 30 or $45 \mathrm{sec}$ ) produced profound disruption of running such that rats typically spent $60 \mathrm{sec}$ in the shocked alleyway rather than enter the shocked goalbox for 30 or $45 \mathrm{sec}$. This would appear to be contrary to the appetitive case, although this has not been examined comparatively.

While studying the partial reinforcement effect (PRE), Woods and his associates noted that each nonreinforcement trial in the cold-water escape runway had a disruptive effect upon each consequent trial and that this produced a trial-by-trial pattern of speeds that has not been observed in the appetitive literature (Woods, Markman, Lynch, \& Stokely, 1972). Another consequence of this disruptive effect of nonreinforcement is that the two published studies on the PRE in a runway escape paradigm which report alley running behavior (Bower, 1960; Woods et al, 1972) both report sharply decreased runway speeds for animals exposed to partial reinforcement. In fact, Bower (1960) reported a striking, inverse, linear relationship between amount of nonreinforcement and speed; and this is certainly not the case for rewarded running at values of $50 \%$ and $75 \%$ reinforcement.

Thus it is possible that nonreinforcement in escape paradigms is far more disruptive (possibly more aversive) than nonreinforcement in reward paradigms. The present experiment fits into this second trend in the small literature on escape behavior-that which illustrates asymmetry between the two kinds of reinforcement. It can also be interpreted in terms of the excessively disruptive effects of nonreinforcement in the shock-escape case. The study was initiated because an early attempt to study contrast with differential conditioning in the shock-escape runway failed when no discriminative behavior emerged.

It is quite common to show that a rat can discriminate between black and white runways on the basis of the correlation of reward or nonreward with runway colors (e.g., Bower, 1961). It is also possible to show that rats can form discriminations in escape paradigms; Woods (1973) has reported this for cold-water, runway escape and Davenport for shock produced barpress escape (Davenport \& Eschenbrenner, 1970). In fact, Woods has emphasized the uniqueness of the general procedure in paradigm classicification and labeled this case "signaled escape."

However, our experience indicated that signaled escape may not procede with the ease that "signaled reward" develops, and the experiment below was designed to demonstrate that point. A direct comparison was made between an appetitive and an aversive group. In all other respects, every attempt was made to keep other variables constant between the two conditions; i.e., the same apparatus, the same discriminative stimulus, etc. 


\section{METHOD}

\section{Subjects}

Twenty male Sprague-Dawley rats weighing between 200 and $250 \mathrm{~g}$ upon arrival from Camm Research, Wayne, New Jersey were divided into a food group $(n=10)$ and a shock group $(n=$ $10)$.

\section{Apparatus}

A straight wooden runway $243.8 \mathrm{~cm}(8 \mathrm{ft})$ long was divided into a $30.5-\mathrm{cm}$ startbox, a $182.9-\mathrm{cm}$ alley and a $30.5-\mathrm{cm}$ goalbox. Each section was separated by a guillotine door. The runway had $7.6 \mathrm{~cm}$ wide and $15 \mathrm{~cm}$ high inside dimensions. Each wall and adjacent floor was composed of an L-shaped shocking surface of galvanized sheet metal. A $1.25-\mathrm{cm}$ gap running lengthwise down the runway floor separated the two shocking surfaces. Clear Plexiglas lids formed the top of each compartment. In all these respects. the device was similar to the shock-escape runways used at Yale University except that it was about $25 \%$ longer in the alleyway. Three $75-\mathrm{W}$ flood lights were suspended at a height of $1 \mathrm{~m}$ above the apparatus over the startbox, the middle of the alley, and the goalbox. When appropriate, covers of opaque dull black cardboard were fastened over the clear Plexiglas lids to produce a completely dark alley. In the absence of the black covering, the runway was brightly lighted by the 3 overhead spotlights. A $2-\mathrm{cm}^{2}$ metal food dish was attached to one wall at the end of the goalbox.

Shock was produced by a $1200-\mathrm{V}$ ac constant-current source with series resistance set to produce a $.80-\mathrm{mA}$ current as measured by an additional $100-\mathrm{K}-\mathrm{ohm}$ resistor placed across the two grids during measurement only. This combination of shocking source and surface has been found to be highly effective in producing runway shock-escape behavior (e.g., Lambert \& Hammond, 1970b).

Photocells were located $7.6 \mathrm{~cm}$ into the alley from the startbox and $7.6 \mathrm{~cm}$ into the goalbox from the alley. Round holes, $5 \mathrm{~cm}$ in diam were cut in the opaque covering above each photocell. Time to travel this $183-\mathrm{cm}(6 \mathrm{ft})$ distance between the photocells was measured to the nearest $1 / 100$ of a sec on a Standard electric clock. Time measures were not transformed into speed scores. All analysies were performed on time data because, as will be seen, the effect of a discrimination when present is to produce the absence of running, not an increase in speed above which would be observed when no discrimination manipulations take place.

\section{Procedure}

Habituation. Prior to the actual experimentation, all rats were placed in groups of 5 in the runway for $5 \mathrm{~min}$ each day for 9 days. During the last 5 days of this procedure, the cover was randomly placed and removed from the top of the runway. The 10 rats in the food group were placed on food deprivation and gradually reduced to $80 \%$ body weight during these 9 days. On the 10th day, each rat in this group was given 2 rewarded goalbox placements.

Discriminative Acquisition. On Days 11-20, each rat was given 5 reinforced $\left(\mathrm{S}_{+}\right)$and 5 nonreinforced $\left(\mathrm{S}_{-}\right)$trials per day or a total of 100 discrimination trials. For rats in the food group, no shock was every delivered, and reinforcement consisted of 3 45-mg Noyes pellets placed in the food dish, while nonreinforcement consisted of no pellets. For the shock group, reinforcement consisted of reduction of the shock from $.80 \mathrm{~mA}$ to $0.0 \mathrm{~mA}$ or complete "relief" immediately upon entrance to the goalbox. On nonreinforced trials, the same level of shock remained on in the goalbox for $30 \mathrm{sec}$. During this time, the rat was not allowed to retrace into the alley. Upon termination of the shock after $30 \mathrm{sec}$, the rat was detained for an additional $30 \mathrm{sec}$ before removal from the goalbox. On all trials for both groups, the rat remained in the goalbox for $1 \mathrm{~min}$. The $\mathrm{S}+$ and

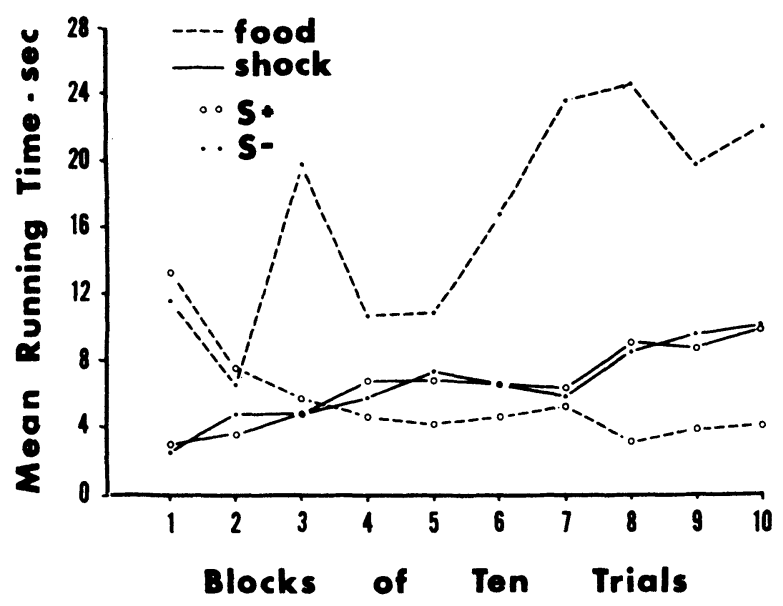

Figure 1. Mean runway latency for both the food group (dashed lines) and the shock group (solid lines) on $\mathrm{S}+$ (open circles) and $S$ - (small dots) trials.

S - trials were signaled by the presence or absence of the black cover over the runway. For half the subjects, the dark cue was consistantly associated with $\mathrm{S}+$ and for the other half of the rats, this cue was consistently associated with $\mathrm{S}$ - trials. On a typical trial, the rat was placed in the startbox after the discriminative cue was in position, and the start gate raised immediately after startbox placement, without concern over the particular behavior of the rat. For rats in the shock group, shock came on simultaneously with the lifting of the startbox gate. The rats were run in groups of 5, with food rewarded rats run first, and the runway was thoroughly cleaned following each day's running. The order of $S+$ and $S-$ trials were randomized with the restriction that $5 \mathrm{~S}+$ and $5 \mathrm{~S}$ - trials occurred each day. All rats received the same random sequence on a given day. In all respects possible, an effort was made to treat the two groups alike in treatment with the obvious exception of drive state and reinforcer.

\section{RESULTS}

The mean running times of the two groups for the S+ and $\mathrm{S}-$ stimuli are shown in Figure 1. As can be seen, the $\mathrm{S}+$ and $\mathrm{S}$ - curves for the food group rapidly diverge (Trials 20-30) and thereafter the difference in mean time is typically in excess of $10 \mathrm{sec}$. On the other hand, the mean $\mathrm{S}+$ and $\mathrm{S}$ - curves for the shock group show no such divergence and are ovbiously covarying. These observations are supported by statistical analyses. In the food group, the mean running time to $\mathrm{S}+$ from trials $51-100$ is $4.10 \mathrm{sec}$ while for $\mathrm{S}-$ it is $21.59 \mathrm{sec}$ (Wilcoxon, matched-pairs, signed ranks, $\mathrm{T}=0, \mathrm{p}<.01$ ). While for the shock group, these comparable means are in the opposite direction ( $\mathrm{S}^{+}=9.01 \mathrm{sec}, \mathrm{S}_{-}=8.12 \mathrm{sec}$; $\mathrm{T}=18, \mathrm{NS}$ ).

Thus, a strong discrimination was shown in the food group with all 10 rats running slower on the average during the $\mathrm{S}-$ than during the $\mathrm{S}+$ for the last half of acquisition. But no discrimination occurred for the shock group with only 4 out of 10 rats running slightly slower to $\mathrm{S}-$ than to $\mathrm{S}+$ during this period. None of 
these four rats showed consistently slower running to $S$ than to $\mathrm{S}+$, and visual inspection of individual curves of each rat in the shock group did not reveal any noticeable discrimination.

\section{DISCUSSION}

The process of comparing such dramatically different conditions in the present experiment is somewhat reminiscent of the problems faced by the comparative learning psychologist (Bitterman, 1965), who must argue, say, that a fish is exposed to learning conditions equal to those for a turtle. However, in the present case, there need be no concern over the sensory dimensions or the degree of response comparability, since the stimuli, apparatus, and species are the same. Nor need there be concern about the effectiveness of the motivation and reward in the food group since this discrimination was formed very well before the point at which acquisition of continuously rewarded runway running reaches its typical asymptote (in our experience, at approximately 75-100 trials).

In contrast, there can be understandable concern over the adequacy of the motivation-reinforcement conditions for the rats in the shock group. Since they showed no discriminative performance, were they equally motivated and reinforced? Although no direct answere can be made to this question, published data from studies with comparable apparatus (e.g., Fowler \& Trapold, 1962; Lambert \& Hammond, 1970b) indicate that rats rapidly acquire escape behavior under conditions highly similar to those for the present shock group and reach asymptotic running speed in 8-12 trials. Unpublished data from the identical apparatus as described in this report, utilizing the same shock level and zero shock reduction on $100 \%$ of the trials, has produced data comparable to these published reports. Indeed as far as can be ascertained in this laboratory, our conditions yield the fastest running behavior of any known technique (see Lambert \& Hammond, 1970b).

Thus if we compare acquisition curves for typical shock-escape and food-reward studies using nondiscriminative procedures, we see that shock-escape procedes 3-5 times more rapidly and, in our particular situation, produces faster running speeds than food reward (note that is not true for the discriminative procedures as in the present experiment). So, on the basis of these nondiscriminative performance criteria from acquisition, the shock conditions produce greater motivation (and presumably more reinforcement) than the hunger-food conditions. Therefore, we conclude that shock-escape discrimination procedes much more slowly (and in fact may never develop at all) under the conditions of the present study.

Given, then, that the demonstration of markedly poorer discrimination performance for shock escape than for food reward is valid, two related questions arise: one, the generality of this finding to all escape procedures and two, the explanation of this poor discriminative performance. Generality, as mentioned in the introduction, does not extend to the broad category of escape behavior. Operant studies of discriminative barpressing for shock escape have been reported (e.g., Davenport \& Eschenbrenner, 1970), and Woods has shown that rats learn signaled escape in the swimway within 52-78 trials based on brightness cues (Woods, 1973). Also, many studies have used shock-escape, T-maze, discrimination procedures (e.g., Overton, 1968). In these studies, the rat has been shown to discriminate on the basis of position cues, drug state, or even differences in shock intensity on different trials. These are simultaneous discrimination procedures wherein a right or left turning response is made on any given trial. Further, such shock-escape, T-maze discrimination on the basis of position cues develops quite rapidly. Cole, Belenky, Boucher, Fernandez, and Meyers (1965) found that rats began to learn a much more difficult probability discrimination between $33 \%$ vs $66 \%$ reinforcement associated with right and left alternatives within 30-50 trials.

Thus rats can learn to discriminate in escape situations. However, only one previous study involved a successive (go, no-go) discrimination (Woods, 1973), and this study used cold-water escape. Therefore, it may be that, although rats can learn to escape with a successive discrimination and can also learn to escape from shock with a simultaneous discrimination, they may not readily learn to escape from shock in a successive discriminative situation.

This leads to the question of why this might be the case. Although we really have no definite answers here, several possibilities can be mentioned. For one, asking a hungry rat to sit in the reward alleyway on a nonreinforced trial is very different from asking it to stay there while being shocked. Thus the payoffs associated with nonresponding are very different in the aversive as opposed to the appetitive case as has been argued elsewhere (Hammond \& Lambert, 1971). For example, the elicitive effects of strong shock upon running must be taken into account. Still, Wood's rats were faced with similar negative payoffs in the cold-water runway and they did learn to slow down on S- trials (Woods, 1973). Secondly, some sort of attentional interpretation might be relevant in which it would be argued that rats experiencing strong shock pay attention to the shock and not to other cue dimensions. Thirdly, and related to the attentional interpretation, it may be true that the shocked rat is primarily responsive to internal stimuli such as drug state or proprioceptive, positional cues and not to external, visual, or auditory stimuli. This would fit with much of the T-maze data.

Finally, these findings may be related in some fashion to the greater disruptive effects of nonreinforcement in the aversive than the appetitive case. As has been mentioned, Woods et al, (1972) found that disruptive effects of nonreinforcement persisted through the intertrial interval to the next trial. Hammond and Lambert (1971) argued that this nonreinforcement is more like punishment than nonreward because there is no definite zero point on the reinforcement dimension. Here, rather than the absence of food, you have delay of shock termination, and there is no guide exactly how long this termination should be delayed. They found that longer delays produced greater disruptions up to the limit of the study's delay values (45 sec, Hammond \& Lambert, 1971).

In the present experiment, a value of 30 -sec delay of shock termination was used on $\mathrm{S}-$ trials. As with the Woods et al (1972) study, these disruptive effects appear to have carried over or generalized to the $\mathrm{S}+$ trials as can be seen by the increasing latencies on $\mathrm{S}+$ as well as $\mathrm{S}-$ trials. One possibility suggested here is that $30 \mathrm{sec}$ was more aversive and consequently more disruptive than the value of delay used in the successful Woods (1973) discrimination study, and this dimension of varying aversiveness of nonreinforcement is the major difference between the aversive and the appetitive case where nonreinforcement has a constant (and distinctly managable) value.

\section{REFERENCES}

Bitterman, M. E. Phyletic differences in learning. American Psychologist, 1965, 20, 396-410.

Bower, G. H. Partial and correlated reward in escape learning. Journal of Experimental Psychology, 1960, 59, 126-130.

Bower, G. H. A contrast effect in differential conditioning. Journal of Experimental Psychology, 1961, 62, 196-199.

Church, R. M. Aversive behavior. In J. W. Kling \& L. A. Riggs (Eds.) Woodworth \& Schlosberg's Experimental Psychology, 1971, 3rd Edition, Volume 2, Pp. 703-741.

Cole, M., Belenky, G. L., Boucher, R. C., Fernandez, R. N., \& Myers, D. S. Probability learning to escape from shock. Psychonomic Science, 1965, 3, 127-128.

Davenport, G. D., \& Eschenbrenner, A. J. Double-intermittent reward wcheduling and secondary-reinforcer strength: Discriminated escape. Psychonomic Science, 1970, 21, 151-153. 
Fowler, H., \& Trapold, M. A. Escape performance as a function of delay of reinforcement. Journal of Experimenta Psychology, 1962, 63, 464-467.

Hammond, L. J. \& Lambert, J. V. Punishing effects of long delays of reinforcement with shock-escape behavior. Psychonomic Science, 1970, 21, 63-64.

Lambert, J. V. \& Hammond, L. J. Effect of frustrative nonrelief upon shock-escape behavior in the double runway. Journal of Experimental Psychology, 1970a, 85, 216-219.

Lambert, J. V. \& Hammond, L. J. Effects of shock source and method of contact upon runway escape behavior. Behavior Research Methods \& Instrumentation, 1970b, 2, 11-13.
Overton, D. A. Visual cues and shock sensititivity in the control of T-maze choice by drug conditions. Journal of Comparative and Physiological Psychology, 1968, 66, 216-219.

Woods, P. J. Signaled escape and signaled punishment. Additional instrumental conditioning paradigms. Bulletion of the Psychonomic Society, 1973, 1, 310-312.

Woods, P. J., Markman, B. S., Lynch, W. C., \& Stokely, S. N. Partial reinforcement effects in instrumental escape conditioning. Learning and Motivation, 1972, 3, 279-292.

(Received for publication September 23, 1974.) 